\title{
Validating a crosscutting simulation program based on computed tomography scanning of logs
}

\author{
Magnus Fredriksson • Anders Berglund · Olof Broman
}

the date of receipt and acceptance should be inserted later

\begin{abstract}
Wood scanners and software for calculating crosscutting positions have been used in the wood industry for some years now. The scanners are used to detect biological and geometrical deviations on the sawn timber, which makes it possible to remove undesired defects using crosscut saws. Yield calculations for crosscutting have not been investigated to the same extent as sawing yield calculations for primary breakdown of logs, especially if the whole chain from log to end product is considered.

nus sylvestris L.) board surfaces. Validating a crosscutting simulation program would mean that it can be used to investigate how raw material and customization of quality rules affect the yield in a wood production chain from log to crosscut end product. The validation showed that crosscutting yield for boards could be predicted with a root mean square error of 13 percentage points, and the technique can be used to identify unsuitable logs for a certain product at an early stage of production.
\end{abstract}

The objective of this study was to validate the result of a computer program developed for simulating crosscutting of boards. The crosscut simulations were performed with respect to knot characteristics on Scots pine ( $P i$ -

Magnus Fredriksson · Anders Berglund · Olof Broman

Division of Wood Science and Engineering, Luleå University of Technology, Forskargatan 1, SE-931 87 Skellefteå, Sweden

Keywords Computed Tomography, Computer Simulation, Crosscutting, Scots Pine, Sawing

\section{Introduction}

During the last three decades, sawmills in the Nordic countries have become more and more technically advanced. Measurement- and scanning equipment are used 
to control different processes and to measure how well various processes perform. The first category includes 3D-scanners in the saw line and scanning equipment at the edger, in the green sorting, trimming plant and further processing. The second category includes scanners for checking positioning errors in the saw, systems to measure green target sizes and systems for following up production disruptions.

This development has increased the use of computers in sawmill production. Automatic grading systems are one example where manual work, earlier made by a manual grader, has been replaced by systems based on computer programs. The data obtained from 3Dscanners, X-ray and computed tomography (CT)-scanners has led to systems for sawing yield calculations, estimating the sawing yield for different sawing patterns. Sawing yield calculations and how they can be optimized with respect to positioning and choice of raw material are important for sawmills in order to maximize profit. For this reason, yield calculations have been a part of numerous studies (Todoroki and Rönnqvist 1999; Rinnhofer et al 2003; Pinto et al 2005; Knapic et al 2011; Berglund et al 2013; Stängle et al 2014).

Yield calculations for further processing have not been investigated to the same extent, especially if the whole chain from log to end product is considered. Lin et al (1995) presents a model of an integrated sawmill and further processing unit, basing their study on 21 red oak (Quercus rubra L.) logs, and Usenius et al (2012) presents the potential gains of a tool capable of linking forest properties to those of an end product.

Two examples of further processing are crosscutting and finger jointing. Crosscutting is normally used for two reasons, to remove unwanted features of a board and to adapt the board to a specified length (Grönlund 1992). Crosscutting can be combined with finger jointing, where the short ends of the wooden pieces that were cut are milled to finger joints. The finger joints are then glued together into desired end products. The aim of a finger jointing process is to maximize yield and minimize waste, while maintaining an acceptable end product quality.

Wood scanners and computer programs for calculating crosscutting positions have been used for some years now. The scanners are used to detect biological and geometrical deviations on the sawn timber, which makes it possible to remove undesired defects using crosscut saws. By biological deviations, we mean any part of the wood that deviates in color or structure to that of the majority of the wood surface, which consists of straight wood fibres oriented parallel to each other. The positions of cuts are governed by an optimization program that maximizes the value of the end products produced out of each board. This optimization process 
means that price and quality rules for the different end products need to be considered, as well as the position of detected defects. Examples of biological features that can be undesirable for an end product are large knots, pitch pockets, rot and blue stain.

When primary sawing yield or crosscutting yield optimization is done in a production system, it is usually done at one production unit at a time, optimizing only that particular unit's performance. This leads to suboptimization since the whole chain from log to a crosscut end product is not considered. A system based thinking, where the whole chain is considered when optimizing, would be more efficient. This could be solved by using CT scanning of logs, together with sawing- and crosscutting simulation. CT scanning and sawing simulation is already widely used, so what is missing is a crosscutting simulation program capable of utilizing data from sawing simulation that in turn utilizes data from CT scanners. Developing and validating a crosscutting simulation program would mean that it can be used to investigate how raw material and customization of quality rules affect the yield in an entire production chain.

The objective of this study was to validate the result of a computer program developed for simulating crosscutting of boards. The crosscut simulations were performed with respect to knot characteristics on board surfaces, resulting from sawing simulation of CT scanned logs. The size and distribution of knots are the most important features for the general impression of a wooden surface. This is why the majority of grading rules are related to knots and why crosscut simulations in our study were focused on knots. A prerequisite for making this study possible was that log breakdown into sawn boards could be simulated as a pre-step. A second objective was consequently to validate the result of such a log breakdown simulation.

\section{Materials and methods}

\subsection{Material}

The study was based on 18 Scots pine (Pinus sylvestris L.) logs that were selected at the logyard of a sawmill in the north of Sweden, from two different sawing classes. They were measured by a RemaLog optical 3D scanner (RemaSawco 2014), and log dimensions were recorded. The top diameters ranged from 156 to $214 \mathrm{~mm}$, and the lengths from 3.4 to $4.9 \mathrm{~m}$. The logs were taken from three different log types: butt logs, middle logs and top logs, six logs from each type, to study the effect of log type on yield in the crosscutting process. Of these six logs, three were taken from one sawing class and three from another, forming six different groups of logs. The $\log$ selection is described in Table 1. 
2.2 Overview of study

The study was done as shown in Figure 1. One part consisted of a real industrial process, where logs were sawn into boards, and boards were crosscut for finger jointing. The corresponding simulations performed were sawing simulation and crosscutting simulation, based on CT data of the logs. Finally, a comparison was made between the results of the two processes.

\subsection{CT scanning logs for simulation}

The logs were scanned with a medical CT scanner (SOMATOM AR.T, Siemens AG). The transportation and storage time from the log yard to the scanning site was three days. The CT scanning took seven days to complete, meaning that the logs were stored between three and ten days from log yard to scanning. During storage and transportation, the logs dried to some extent. However, the drying was not extensive and did not affect the results of knot detection and classification. The results from the scanning were $512 \times 512$ pixel image stacks of each log, with a voxel size of $0.68 \times 0.68 \times$ $5.34 \mathrm{~mm}$. A knot detection algorithm developed by Johansson et al (2013) was used on the image stacks. This resulted in a parametrized description of the knots in the log, which was used for subsequent sawing simulation. The algorithm works on so called concentric sur- faces, which are cylindrical surfaces on regular radial distances to the pith of the log. In the concentric surfaces, knots are detected and fitted to ellipse shapes. Ellipse shapes are then used for parametrization, which is based on the regression models presented in Table 2 (Johansson et al 2013). Further information can also be found in Grönlund et al (1995) and Andreu et al (2003). The parametrized description includes the knots position, size and the position of the dead knot/sound knot border. The outer shape of the logs was also obtained from the CT image stacks. When scanning the logs, the rotational position of each log was marked with a felt tip pen on the butt end of the log, by drawing an arrow. The reason for this was to be able to simulate sawing of the logs in the same position as in the real sawmill.

\subsection{Sawing the logs}

The logs were sawn at the sawmill together with other logs in the same sawing class. The sawmill had two sawing machines with circular sawblades, sawing a cant in the first saw and splitting it in the second saw. The second saw employed curve sawing. In the first saw, images of the butt end of each log were recorded using a video camera during sawing. This made it possible to estimate the rotational position for each log that was sawn, which is shown in Figure 2. Logs were sawn as 
centered as possible, and the sawing patterns used are presented in Figure 3 .

Only the center boards were used in this study. They were kiln dried to a moisture content of $12 \%$, and no trimming of the board ends was carried out. Each board was manually graded by a professional grader, into three different quality grades, A, B and C. This was done according to the Nordic Timber Grading Rules (Swedish Sawmill Managers association 1994), where grade A has the strictest requirements. However only knots and wane were used for grading, to be able to compare the results to the sawing simulation which was made using knot- and outer shape information. The grading criteria for knots and wane according to the Nordic Timber Grading Rules are presented in Table 3. These criteria are for the board dimension used in this study, $50 \times 100 \mathrm{~mm}$. Figure 4 shows how knot sizes are defined depending on type of knot.

\subsection{Sawing simulation}

The result of the CT scanning (log outer shape, knot descriptions) were used for sawing simulation, by the simulation program Saw2003 developed by Nordmark (2005). The simulation program has been used extensively in earlier research (Chiorescu and Grönlund 2000; Nordmark 2005; Moberg and Nordmark 2006; Lundahl and Grönlund 2010). Saw2003 uses CT scanned logs as input data, and models a sawmill that employs cant sawing with two sawing machines, and curve sawing in the second saw.

To ensure that logs were sawn in similar positions in the sawing simulation as in reality, the logs were sawn several times in Saw2003, in different sawing positions close to the rotation indicated by the drawn arrow on the video images from the real sawing. The resulting boards were compared to images of the real boards, until a sawing position close to the real one was achieved. This comparison was done manually, matching the knots on the boards.

Grading of the boards resulting from sawing simulation was done according to the Nordic Timber Grading Rules (Swedish Sawmill Managers association 1994). The grading was based on knots and wane only, since other board features, such as pitch pockets or rot, were not represented in the log descriptions. Grading is done automatically in Saw2003. Board surfaces are created by calculating cutting planes through the log, that contains the parametrized knot model. Thus, board surfaces with shape and size of visible knots can be calculated and then used for grading.

\subsection{Scanning and crosscutting the boards}

The real boards were scanned and optimized for crosscutting using an industrial board scanner, WoodEye 
(Innovativ Vision 2014). The scanner was equipped with four grey-scale line cameras, and the camera images were used for detection and classification of board features. These features were used for crosscutting decisions. The data stored for each feature was feature type, position in the length- and crosswise direction of the board, and size in the length- and crosswise direction of the board. The product made in the crosscutter was pieces for subsequent finger jointing, so it was a product with flexible length. Allowed lengths of crosscut pieces were 170-550 mm. Pieces 170-285 mm were valued differently from pieces $285-550 \mathrm{~mm}$, for the sake of optimization. If the value of $170-285 \mathrm{~mm}$ pieces are normalized to 100 , the relative value of pieces $285-550 \mathrm{~mm}$ was 103. The reasoning behind this was to produce more of longer lengths, which are easier to handle in the production process. Crosscutting decisions were made on knots and wane only, to be able to compare the crosscutting decisions and yield to the simulation results. Knots were classified as dead or sound, depending on color. All board features were classified as either accepted or rejected, depending on a set of quality rules defined in Table 4. If both quality limits for length and width were exceeded, the feature was considered as a defect and was cut away. The rest of the wood was considered accepted, as long as there was a $15 \mathrm{~mm}$ knot-free zone at the end of each crosscut piece.

\subsection{Crosscutting simulation}

Using the boards that resulted from the sawing simulation, a crosscutting simulation program was written.

The crosscutting optimization is based on the principles described in Rönnqvist and Åstrand (1998). The program classifies knots and wane as allowed or not allowed, using exactly the same grading rules as the WoodEye crosscutting optimizer, Table 4. This preprocessing divides the board into zones from where products can be cut out, or not. Using these results, the crosscut decisions are made, optimizing the value of the product mix made from each board. The value for each product is fixed and defined before-hand, as value per produced meter of material. In this case, the same product mix and relative values were used as in the WoodEye optimizer.

\section{Results}

\subsection{Validation of the sawing simulation}

To have a functioning simulation model of the process of turning a log into a crosscut and finger jointed board, the log sawing process needs to be modelled correctly. To validate the sawing simulation program Saw2003 was therefore one of the objectives of this study. It was made by comparing the resulting board grades from Saw2003 to the grades of real boards, the latter grad- 
ing being done manually by a professional grader. Since there was no information about which board was the left and the right in the sawing pattern, the boards were treated together in pairs, or in triplets for the larger sawing pattern. For instance, if both the manual grading and the simulated grading resulted in one $A$ board and one $C$ board, it was considered as two boards with the same grade regardless of which board was which. With these assumptions, $71 \%$ of the boards had the same grade. For none of the boards the difference was more than one grade, which can be observed in Table 5 showing the grade distribution.

\subsection{Validation of the crosscutting simulation}

The other objective was to validate the crosscutting simulation program. The crosscutting yield for each board was calculated, both for the results of the crosscutting simulation program and the industrial process. The crosscutting yield $Y_{c c}(\%)$ was defined as

$Y_{c c}=100 \times \frac{L_{\text {out }}}{L_{\text {in }}}$

where $L_{i n}=$ length of input material (the board), and $L_{\text {out }}=$ total length of output material (crosscut pieces). The crosscutting yield for all boards is presented in Figure 5. The root mean square error (RMSE) of the crosscutting yield was 13 percentage points, be- tween the simulation program and the industrial process.

Total yield for each log was also calculated, for the results of the crosscutting simulation program and the industrial process. The total yield $Y_{\text {tot }}(\%)$ was defined as

$Y_{t o t}=100 \times \frac{V_{b o a r d s}}{V_{l o g}}$

where $V_{\text {boards }}=$ total dry volume of output material (crosscut pieces) from one log, and $V_{l o g}=$ volume of the green log. The log volume was the volume measured by the $3 \mathrm{D}$ scanner at the sawmill.

Total yield for the $18 \operatorname{logs}$ is shown in Figure 6, where logs are marked by log type. The RMSE of the total yield was 3.9 percentage points.

The allowed length interval for crosscut pieces of 170-550 mm was divided into $20 \mathrm{~mm}$-intervals. In each length interval, the number of crosscut pieces were counted, both for the simulation results and for the WoodEye optimizer. This created a distribution that is presented in Figure 7.

\section{Discussion}

In this paper it has been shown that a crosscutting simulation program utilizing data from CT scanning and sawing simulation of logs results in similar crosscutting 
results as a system used in the industry. The plot in Figure 5 shows that the crosscutting yield of a board for a certain production setup can be predicted well. The root mean square error of the simulation model compared to the industrial process was 13 percentage points, an error containing the entire process from log to crosscut board. It indicates that the CT scanning, knot parametrization and sawing simulation results in boards with realistic knot sizes and positions. The two outlier boards in the top left quarter of Figure 5 was examined in detail, and this examination showed that the WoodEye classified many knots on these boards as dead, whereas the knot parametrization algorithm, forming the input data for sawing simulation, classified them as sound. Since no dead knots were allowed in the quality rules used, this had a large impact on yield. It explains why the WoodEye yield is smaller than the yield obtained from crosscutting simulation in these two cases.

Furthermore, the length distribution of crosscut pieces in Figure 7 is rather similar between the WoodEye optimizer and the developed program. This length distribution depends on the knot structure of the input material, together with the optimization algorithm and the product values used in the optimization. For instance, in Figure 7 there is a large amount of pieces produced near the maximum length of $550 \mathrm{~mm}$. This can be explained by the fact that longer pieces give less cuts and therefore a higher produced volume. The effect is that in very long segments of acceptable quality, 550 mm pieces will be chosen exclusively. Altogether this shows that the actual optimization, together with the detection of knots and sawing simulation, gives similar results when comparing the simulation to the industrial process.

The board grades resulting from sawing simulation was the same as the results of a manual grader for 71 $\%$ of the boards. This can be compared to the agreement between two professional graders, that can be as low as 55-57 \% (Grundberg and Grönlund 1997). This, together with the matching that was made between boards resulting from sawing simulation to images of the real boards, shows that Saw2003 results in sawn timber similar to that of a real sawing process. However this was done for the total outcome of a log, i.e. two or three boards together. Our study does not show how well the quality of individual boards can be predicted, just the outcome of sawing logs.

Other possible sources of error apart from the crosscutting simulation program itself are the CT scanning, that can give rise to images with noise and artefacts, the knot reconstruction algorithm, the sawing simulations, and the industrial scanner. The knot reconstruction algorithm, as described in Johansson et al (2013), will not 
find all knots in a log. The hit rate is around $94 \%$ for Scots pine. Also, around $1 \%$ of knots found by the algorithm are false positives, i.e. a knot is found where there is none. The sawing simulation program Saw2003 has been validated through its predecessor vSM that was tested by Chiorescu and Grönlund (2000), and shows good conformity to a real sawmill. The test made in our paper showed that the conformity in terms of sawn timber quality between Saw2003 and a real quality grading was rather good, albeit not perfect. Finally, the industrial scanner is not perfect either, there are always errors present in the scanning of the boards and in the classification of board features. However, using the industrial scanner as reference meant that the developed crosscutting simulation program was compared to what it is meant to model, i.e. an industrial process.

The results should be interpreted while keeping in mind that the amount of logs used was limited. Also, the results were obtained using Scots pine logs. This means that it is not certain whether the method works in the same way for other species, that might have a different knot structure than Scots pine.

In research, the developed program can be used together with log databases to investigate how raw material, quality rules and crosscutter settings affect the end result in the form of crosscut products for various end uses. One interesting data set to study in this context, is the Swedish stem bank. It contains CT-data from about 600 Scots pine (Pinus sylvestris) logs (Grönlund et al 1995) and about 800 Norway spruce (Picea abies) logs (Berggren et al 2000). Also, industrial CT scanners are being made available (Giudiceandrea et al 2011), something which will increase the amount of data that is available for simulation studies.

A practical use of this simulation program in the industry is possible if a sawmill has an installed CT scanner for scanning of logs. Simulation technique can then be used to predict how well suited a log is for further processing, thus controlling the flow of material. This would enable the sawmill to find other uses for the unsuitable logs, which would increase raw material efficiency. An indication that this would work is given in Figure 6, where the total yield of each log is predicted quite well by the crosscutting simulation program. The material of 18 logs is however too small to draw any definite conclusions from.

There are errors present when comparing the simulation results to the industrial process, however many of these errors will not affect the results when the program is used to do comparative simulation studies, testing different possible cases within the simulation environment itself. This approach will mitigate the effect of for instance log model errors, since all tested cases will be based on the same log models. For this reason 
it is highly recommended that any conclusions drawn from future simulation studies are done based on relative values when comparing cases, rather than absolute values.

Future work can include using this simulation program for various studies, such as how log characteristics influence end product properties, how sawing and crosscutting can be controlled to ensure a high process efficiency, or the impact of quality rules on yield and end product properties.

\section{Conclusions}

It can be concluded that both the sawing simulation program and the crosscutting simulation program can be used to predict the outcome of real sawing and crosscutting processes. Sawing simulation results in a board quality that is the same as that of a professional grader for $71 \%$ of boards, and the crosscutting yield of individual boards can be predicted with a root mean square error of 13 percentage points using the crosscutting simulation program.

\section{References}

Andreu JP, Rinnhofer A, Rinnhofer A (2003) Modeling of internal defects in logs for value optimization based on industrial CT scanning. In: Fifth International Confer- ence on Image Processing and Scanning of Wood, 23-26 March 2003, Bad Waltersdorf, Austria, pp 23-26

Berggren G, Grundberg S, Grönlund A, Oja J (2000) Improved spruce timber utilisation (STUD). Tech. rep., Luleå University of Technology and AB Trätek, European shared cost research project within FAIR (DGXII/E2), contract no. FAIR-CT96-1915. Final report sub-task A 1.2. Database and non-destructive "Glass-log" measurements

Berglund A, Broman O, Grönlund A, Fredriksson M (2013) Improved log rotation using information from a computed tomography scanner. Computers and Electronics in Agriculture 90(2):152-158

Chiorescu S, Grönlund A (2000) Validation of a CT-based simulator against a sawmill yield. Forest Products Journal 50(6):69-76

Giudiceandrea F, Ursella E, Vicario E (2011) A high speed CT scanner for the sawmill industry. In: Proceedings of the 17th International Non Destructive Testing and Evaluation of Wood Symposium, 14-16 September 2011, University of West Hungary, Sopron, Hungary

Grönlund A (1992) Sågverksteknik del II - Processen (Sawmill Technology part II - The Process). Sveriges skogsindustriförbund, Markaryd, Sweden, in Swedish

Grönlund A, Björklund L, Grundberg S, Berggren G (1995) Manual för furustambank (Manual for Pine Stem Bank). Tech. Rep. 19, Luleå tekniska universitet, Luleå, in Swedish

Grundberg S, Grönlund A (1997) Simulated grading of logs with an x-ray log scanner-grading accuracy compared with manual grading. Scandinavian Journal of Forest Research 12(1):70-76 


\section{Innovativ Vision (2014) WoodEye English.} http://www.woodeye.se/en/, accessed 21st of January 2014

Johansson E, Johansson D, Skog J, Fredriksson M (2013) Automated knot detection for high speed computed tomography on Pinus sylvestris L. and Picea abies (L.) Karst. using ellipse fitting in concentric surfaces. Computers and Electronics in Agriculture 96(4):238-245

Knapic S, Seppä IP, Usenius A, Pereira H (2011) Stem modeling and simulation of conversion of cork oak stems for quality wood products. European Journal of Forest Research 130(5):745-751

Lin W, Kline ED, Araman PA, Wiedenbeck JK (1995) Design and evaluation of log-to-dimension manufacturing systems using system simulation. Forest Products Journal $45(3): 37-44$

Lundahl CG, Grönlund A (2010) Increased yield in sawmills by applying alternate rotation and lateral positioning. Forest Products Journal 60(4):331-338

Moberg L, Nordmark U (2006) Predicting lumber volume and grade recovery for Scots pine stems using tree models and sawmill conversion simulation. Forest Products Journal $56(4): 68-74$

Nordmark U (2005) Value recovery and production control in the forestry-wood chain using simulation technique. $\mathrm{PhD}$ thesis, Luleå University of Technology, Luleå, Sweden

Pinto I, Usenius A, Song T, Pereira H (2005) Sawing simulation of maritime pine (pinus pinaster ait.) stems for production of heartwood containing components. For Prod J $55(4): 88-96$

RemaSawco (2014) Sawco AB. http://www.sawco.se/, accessed 5th of May 2014
Rinnhofer A, Petutschnigg A, Andreu JP (2003) Internal log scanning for optimizing breakdown. Computers and Electronics in Agriculture 41(13):7-21, developments in Image Processing and Scanning of Wood

Rönnqvist M, Åstrand E (1998) Integrated defect detection and optimization for cross cutting of wooden boards. European journal of operational research 108(3):490-508

Stängle SM, Brüchert F, Heikkila A, Usenius T, Usenius A, Sauter UH (2014) Potentially increased sawmill yield from hardwoods using X-ray computed tomography for knot detection. Annals of Forest Science pp 1-9

Swedish Sawmill Managers association (1994) Nordic Timber: Grading rules for pine (Pinus sylvestris) and spruce (Picea abies) sawn timber: Commercial grading based on evaluation of the four sides of sawn timber. Föreningen svenska sågverksmän (FSS), Sweden

Todoroki CL, Rönnqvist E (1999) Combined primary and secondary $\log$ breakdown optimisation. Journal of the Operational Research Society 50(3):219-229

Usenius A, Heikkilä A, Usenius T, Makkonen M (2012) Converting product requirements into wood raw material specifications. In: Proceedings of the IUFRO all Division 5 conference, 8-11 July 2012, Estoril, Portugal, p 128 
Figures

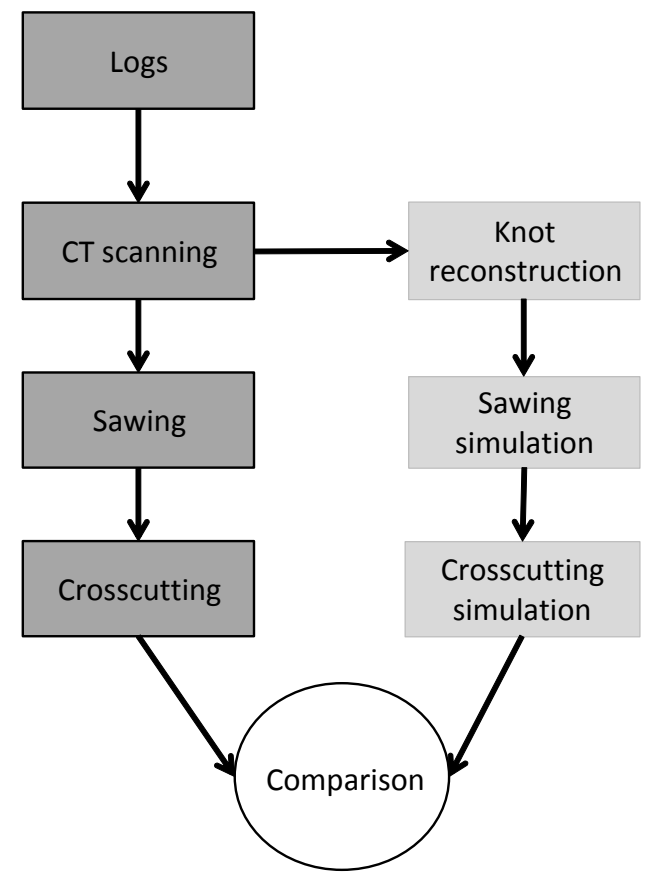

Fig. 1 Flowchart of this study. The left hand side, in dark grey, corresponds to the activities done in the real sawing and crosscutting process. The right hand side, in light grey, corresponds to the simulations that were done.

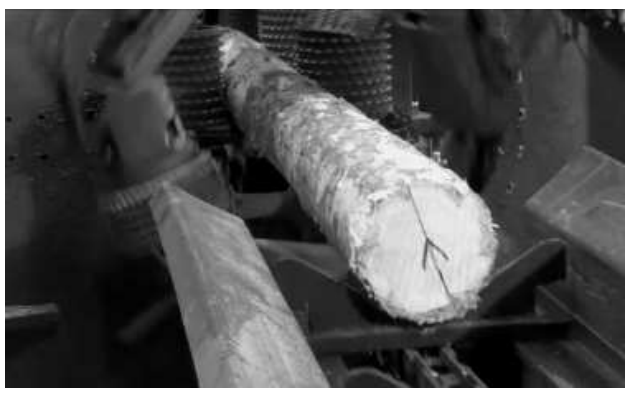

Fig. 2 Example image of log being sawn. A drawn arrow indicating the rotational direction of $\mathrm{CT}$ scanning is visible in the butt end of the log.

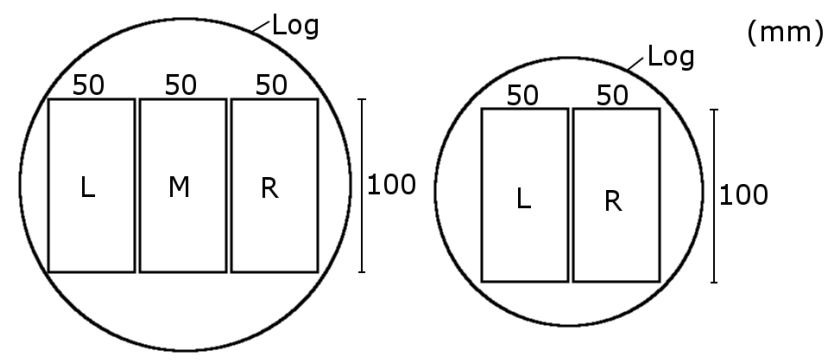

Fig. 3 The two sawing patterns used in this study, with nominal board dimensions. Each log was sawn into a cant that was rotated and split into two or three center boards. $\mathrm{L}=$ left board, $\mathrm{M}=$ middle board, and $\mathrm{R}=$ right board. Side boards were also sawn, but they were not used in this study and are therefore not shown in this figure.

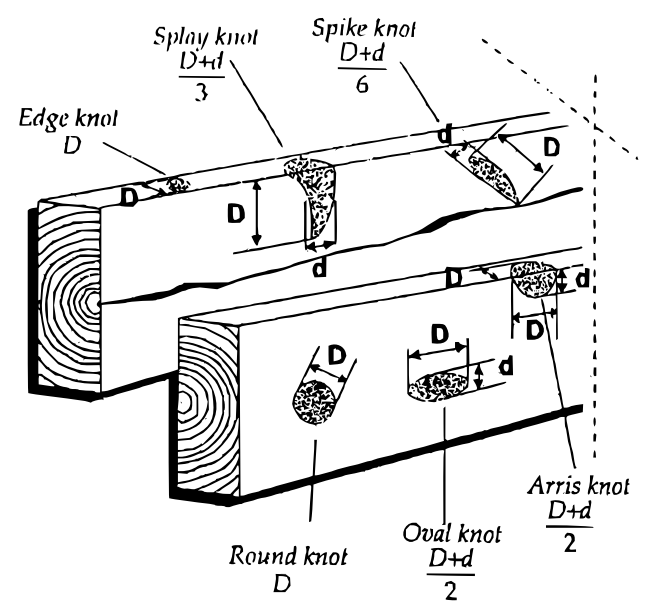

Fig. 4 Definition of knot sizes according to the Nordic Timber Grading Rules

(Swedish Sawmill Managers association 1994). 


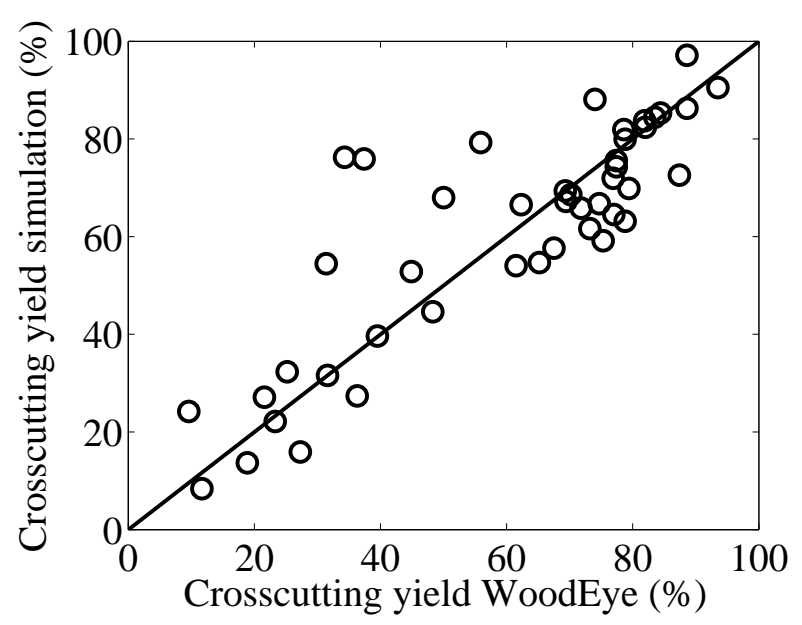

Fig. 5 Crosscutting yield for all boards of the study, using the crosscut simulation program of this article compared to the WoodEye scanner and optimizer. An identity line is included as reference.

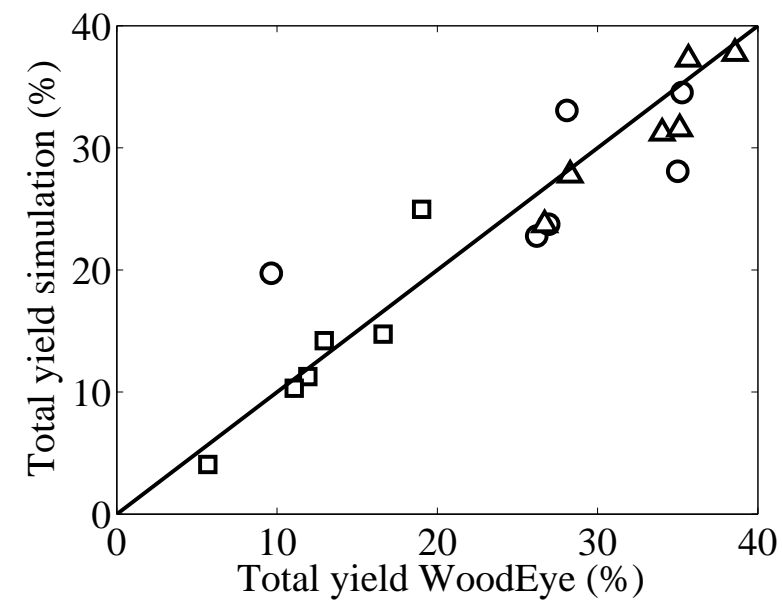

Fig. 6 Total yield for the 18 logs of this study, using the crosscut simulation program of this article compared to the WoodEye simulation program. Squares $=$ butt logs, triangles $=$ middle logs, and circles $=$ top logs.

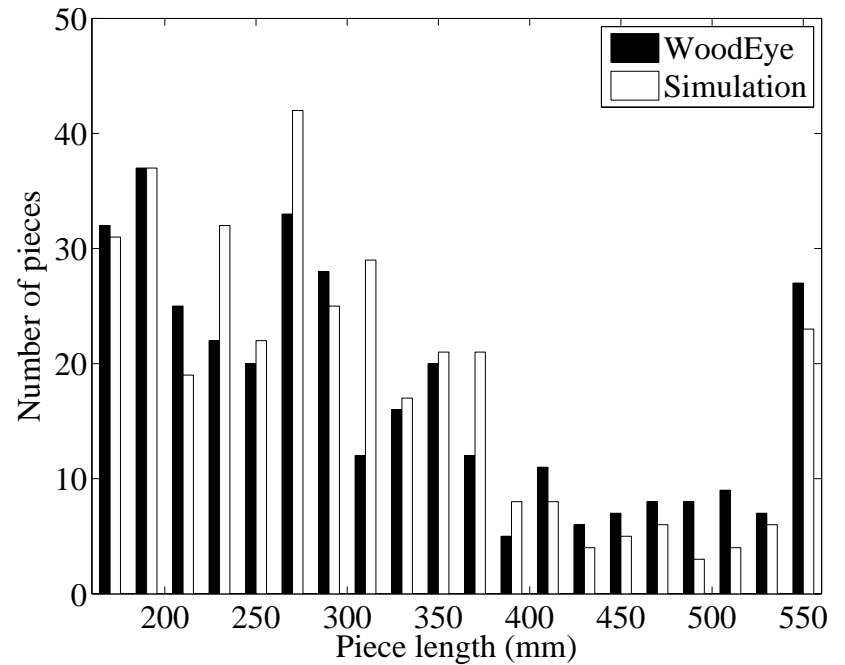

Fig. 7 Lengths of crosscut pieces produced by the WoodEye scanner and optimizer compared with the developed crosscut simulation program. The width of the bars is $20 \mathrm{~mm}$ in the range from $170 \mathrm{~mm}$ to $550 \mathrm{~mm}$. 
Tables

Table 1 Log data. Both the nominal top diameter range of the sawing class and the actually measured top diameter range of the logs in this study are presented.

\begin{tabular}{|c|c|c|c|c|c|c|}
\hline \multirow{2}{*}{ Log type } & \multicolumn{2}{|c|}{ Butt log } & \multicolumn{2}{c|}{ Middle log } & \multicolumn{2}{c|}{ Top log } \\
\hline Group & 1 & 2 & 3 & 4 & 5 & 6 \\
\hline Sawing pattern & 2 center & 3 center & 2 center & 3 center & 2 center & 3 center \\
& boards & boards & boards & boards & boards & boards \\
& $50 \times 100$ & $50 \times 100$ & $50 \times 100$ & $50 \times 100$ & $50 \times 100$ & $50 \times 100$ \\
\hline $\begin{array}{c}\text { Sawing class top diameter } \\
\text { range (mm) }\end{array}$ & $156-167$ & $194-210$ & $156-167$ & $194-210$ & $156-167$ & $194-210$ \\
\hline $\begin{array}{c}\text { Measured top diameter } \\
\text { range of logs (mm) }\end{array}$ & $161-168$ & $206-214$ & $160-165$ & $200-210$ & $156-164$ & $194-204$ \\
\hline
\end{tabular}

Table 2 Knot parametrization models as described by Johansson et al (2013). A-I are the 9 parameters used for describing knot position and size, and are different between different knots. $r=$ radial distance to pith.

\begin{tabular}{cc}
\hline Knot diameter (rad) & $\phi(r)=A+B r^{1 / 4}$ \\
Lengthwise position (mm) & $z(r)=C+D \sqrt{r}+E r$ \\
Angular position (rad) & $\omega(r)=F+G \ln (r)$ \\
Knot end (mm) & $H$ \\
Dead knot border (mm) & $I$ \\
\hline
\end{tabular}


Table 3 Knot and wane restrictions according to the Nordic Timber Grading Rules, for grades A, B and C, and for the board dimension used in this study. Dead knot limits are $70 \%$ of green knot limits. For wane, '\%' refers to percentage of the board length or thickness. All criteria are given as maximum limits, so all features must fall below the limits for the board to pass a certain grade. The number of knots are multiplied by the size of knots to give a knot area, at the worst $1 \mathrm{~m}$ length of the board. (Swedish Sawmill Managers association 1994).

\begin{tabular}{|c|c|c|c|}
\hline Board feature & Grade A & Grade B & Grade C \\
\hline Number of knots, flat side & 4 & 5 & 6 \\
\hline Number of knots, edge & 2 & 3 & 4 \\
\hline \multicolumn{4}{|l|}{ side } \\
\hline Flat side knot size (mm) & 30 & 45 & 60 \\
\hline Edge side knot size $(\mathrm{mm})$ & 30 & 40 & 50 \\
\hline Wane length, one edge & 20 & 30 & 40 \\
\hline \multicolumn{4}{|l|}{$(\%)$} \\
\hline Wane length, two edges & 10 & 20 & 30 \\
\hline \multicolumn{4}{|l|}{$(\%)$} \\
\hline Wane depth, per edge side & 10 & 15 & 20 \\
\hline \multicolumn{4}{|l|}{$(\%)$} \\
\hline Wane width (mm) & 7 & 12 & 17 \\
\hline
\end{tabular}

Table 4 Quality rules for crosscutting in this study. Length and width of features are defined using the board, i.e. feature length is size in the lengthwise direction of the board. If a feature is larger than the maximum length and width, it is considered unwanted and is cut away.

\begin{tabular}{ccc}
\hline Feature & Maximum length $(\mathrm{mm})$ & Maximum width $(\mathrm{mm})$ \\
\hline Sound knot & 50 & 50 \\
Dead knot & Not allowed & Not allowed \\
Wane & 5 & 2.5 \\
\hline
\end{tabular}


Table 5 Comparing grades assigned to boards from sawing simulation based on CT scanning of logs, and boards sawn from the same logs that were manually graded. The sawing simulation grading results are read column wise and the manual grading results are read row wise.

\begin{tabular}{|c|c|c|c|c|}
\hline & \multicolumn{3}{|c|}{ Sawing simulation } & \multirow[b]{2}{*}{ Total } \\
\hline & A & $\mathrm{B}$ & $\mathrm{C}$ & \\
\hline A & 10 & 2 & 0 & 12 \\
\hline B & 2 & 17 & 6 & 25 \\
\hline $\mathrm{C}$ & 0 & 3 & 5 & 8 \\
\hline Total & 12 & 22 & 11 & 45 \\
\hline
\end{tabular}

Total agreement: $(10+17+5) / 45=71 \%$ 